\title{
EXCAVACIONES EN EL "PARAJE DE LAS DEHESAS" (OSMA, SORIA): ESTUDIO TRACEOLÓGICO DE UNA FICHA ROMANA DE JUEGO
}

\section{Excavation of "Paraje de las Dehesas" (Osma, Soria, Spain): Traceological study of a Roman Game Roundel}

\author{
Durán Cabello, R. ${ }^{1}$; Barrio Onrubia, R. ${ }^{2}$; Martín Lerma, I. ${ }^{3}$; Gutiérrez Sáez, C. ${ }^{4}$; \\ Arellano Hernández, 0.5; Lerín Sanz, M. ${ }^{6}$; Ruiz de Marco, A.7; \\ Tarancón Gómez, M. J. ${ }^{8}$
}

Recibido el 15 de julio de 2009. Aceptado el 10 de septiembre de 2009

\begin{abstract}
Resumen. Durante las recientes excavaciones desarrolladas en el yacimiento de Uxama (Soria), se ha recuperado, entre otros materiales, una ficha de juego romana. El objetivo de este trabajo ha sido un estudio traceológico de esta pieza, inacabada, para una mejor determinación de los procesos de fabricación. Palabras clave: ciudad romana, tecnología, traceología, cultura material, calculus.
\end{abstract}

Abstract. During the recent excavations that were undertaken at the site of Uxama (Soria), a partly finished roman game roundel (chip) was retrieved, between other materials. This study describes the traceological analysis that was carried out in order to better understand the technical features of this object.

Keywords: roman city, technology, traceology, material culture, calculus.

\section{INTRODUCCIÓN}

Este trabajo es un avance de los resultados de las excavaciones Ilevadas a cabo en el yacimiento de Uxama, concretamente en el paraje de "Las Dehesas" en Osma (Soria) (fig. 1). Con motivo de las obras de construcción de una residencia para la tercera edad, se realizó una intervención arqueológica, durante el año 2007, que nos ha permitido conocer parte del entramado urbano de esta ciudad romana.

\section{EL YACIMIENTO}

\subsection{La calle}

Se ha descubierto una calle de trazado rectilíneo, con dirección noreste-sureste, de 50 metros de longitud, lo que confirma que se trata de un cardo menor. La superficie de esta calle presenta una sección convexa, constituida por un relleno compactado de cantos cuarcíticos, piedras calizas y arena. Este tramo puede ser la continuación de los vestigios

(1) Dpto. de Prehistoria y Arqueología. UAM. Madrid. Campus de Cantoblanco, Ctra. de Colmenar, km. 15, 28049 Madrid. rosalia.duran@uam.es $\left({ }^{2}\right)$ Arquetipo S. C. L. Carretera de Logroño 1, bajo, 42004 Soria. raquel.arquetipo@telefonica.net

(3) Dpto. de Prehistoria y Arqueología. UNED. Edificio Humanidades, Senda del Rey 7, 28040 Madrid. imartin@bec.uned.es.

$\left.{ }^{4}\right)$ Dpto. de Prehistoria y Arqueología. UAM. Campus de Cantoblanco, Ctra. de Colmenar, km. 15, 28049 Madrid. carmen.gutierrez@uam.es

(5) Arquetipo S. C. L. Carretera de Logroño 1, bajo, 42004 Soria. oscar.arquetipo@telefonica.net

(6) Arquetipo S. C. L. Carretera de Logroño 1, bajo, 42004 Soria.montse.arquetipo@telefonica.net

(7) Arquetipo S. C. L. Carretera de Logroño 1, bajo, 42004 Soria.agustin.arquetipo@telefonica.net

$\left({ }^{8}\right)$ Arquetipo S. C. L. Carretera de Logroño 1, bajo, 42004 Soria. chus.arquetipo@telefonica.net 
- Figura 1. Calle localizada en el paraje de "Las Dehesas".

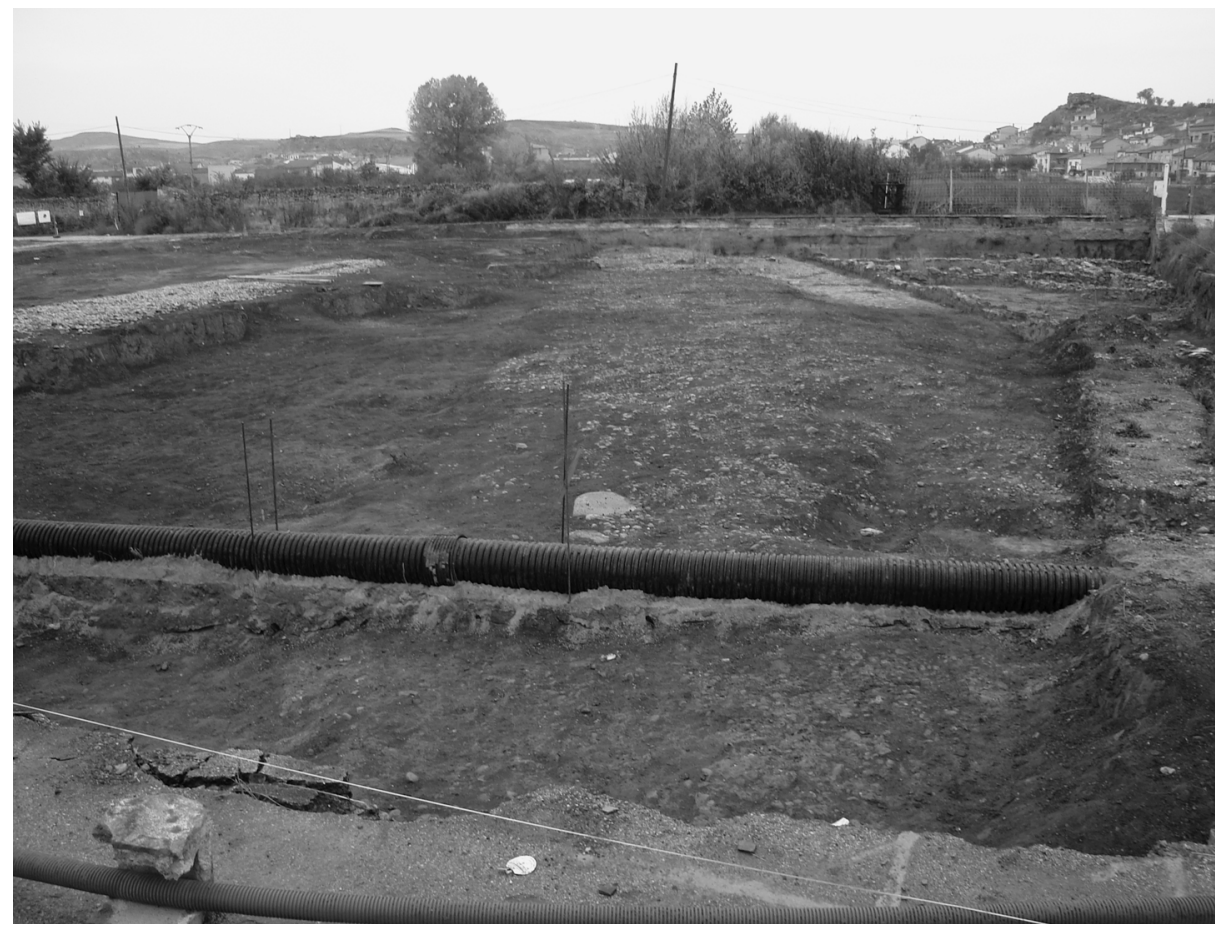

documentados a partir de la excavación (Arellano et al. 1999) acometida en el solar situado inmediatamente al sur y de una fotografía aérea ${ }^{9}$, en la que se puede apreciar el crecimiento diferencial de la vegetación, marcando así una banda más clara que coincide con la dispersión de los restos y asegura su continuidad por ambos extremos.

Durante los trabajos de 2007, se ha atestiguado un canal, perpendicular a la estructura viaria, que permite plantear que la calle hubiera estado surcada por una serie de canalillos para facilitar la evacuación de las aguas pluviales. La anchura de la vía es de 7,5 metros y la potencia, con un máximo de 1 metro, está constituida por la superposición de cuatro capas de árido que asientan sobre el nivel natural. Este dato viene a reafirmar lo apuntado por Moreno (2002: 115-116) para el firme de las calzadas romanas, y más concretamente, para la Vía 27, que discurre por el casco urbano de 0 sma $^{10}$. Sin embargo, la calle descubierta en "Las Dehesas" es, sin género de duda, una vía urbana, lo que queda corroborado por la existencia, en ambas márgenes, de sendos edificios, a una distancia de aproximada 2,5 metros por el noreste y 12 metros por el suroeste.

Es conocido que aunque la anchura de las calles puede variar, se ajusta a un estándar en torno a los 4 ó 5 metros. No obstante, el espacio de pared a pared presenta variaciones, llegando a superar los 12 m cuando existe pórtico (Adam 1996: 304-305). Los indicios de presencia de un soportal se manifiestan en un pilar ubicado en el límite noroeste del encachado, adosado al edificio de ese lado.

\subsection{Los edificios}

Apenas quedan restos visibles de los alzados de los edificios, si bien, lo que permite reconocer su existencia son las cimentaciones. La orientación de estos edificios es de noroeste a sureste, en paralelo con el vial, coincidiendo con la urbanística registrada en la zona.

Las cimentaciones están construidas con mampostería de piedra caliza, de tamaño medio, ligeramente careada y trabada con tierra (fig. 2). Su anchura varía de 0,30 a 0,85 metros, correspondiendo las más potentes con las localizadas en la acera suroeste. La altura oscila entre 0,10 y 0,87 metros, lo que supone de una a cinco hiladas, dependiendo del grado de alteración al que se han visto sometidas. La profundidad viene motivada, no tanto por la altura del edificio, como por la necesidad de asegurar su protección ante los efectos de la humedad y las oscilaciones térmicas.

En cuanto a los alzados, se realizaron con tapial (arcilla desengrasada con arena), como se documenta ampliamente en las excavaciones realizadas en el yacimiento de Uxama (Garcia Merino 1991, 1995 y 2005; Durán Cabello 1998: 9697). En el transcurso de la excavación se ha comprobado que el derrumbe de los muros de tapial colmataba las estancias. Se ha documentado que el tapial tenía refuerzos de un entramado de madera, cuya huella puede ser detectable por la gran abundancia de clavos localizados de diversos tamaños. Muchos de ellos, debieron pertenecer a la armazón de la cubierta del edificio (Fernández Vega 1993: 46).

(9) Procede de un vuelo de los años 1999-2000 y obra en poder del Sistema de Información Territorial de Castilla y León.

$\left({ }^{10}\right)$ Se desconoce su trazado desde el limite de término, por el este, hasta el final del caserío, por el oeste. 


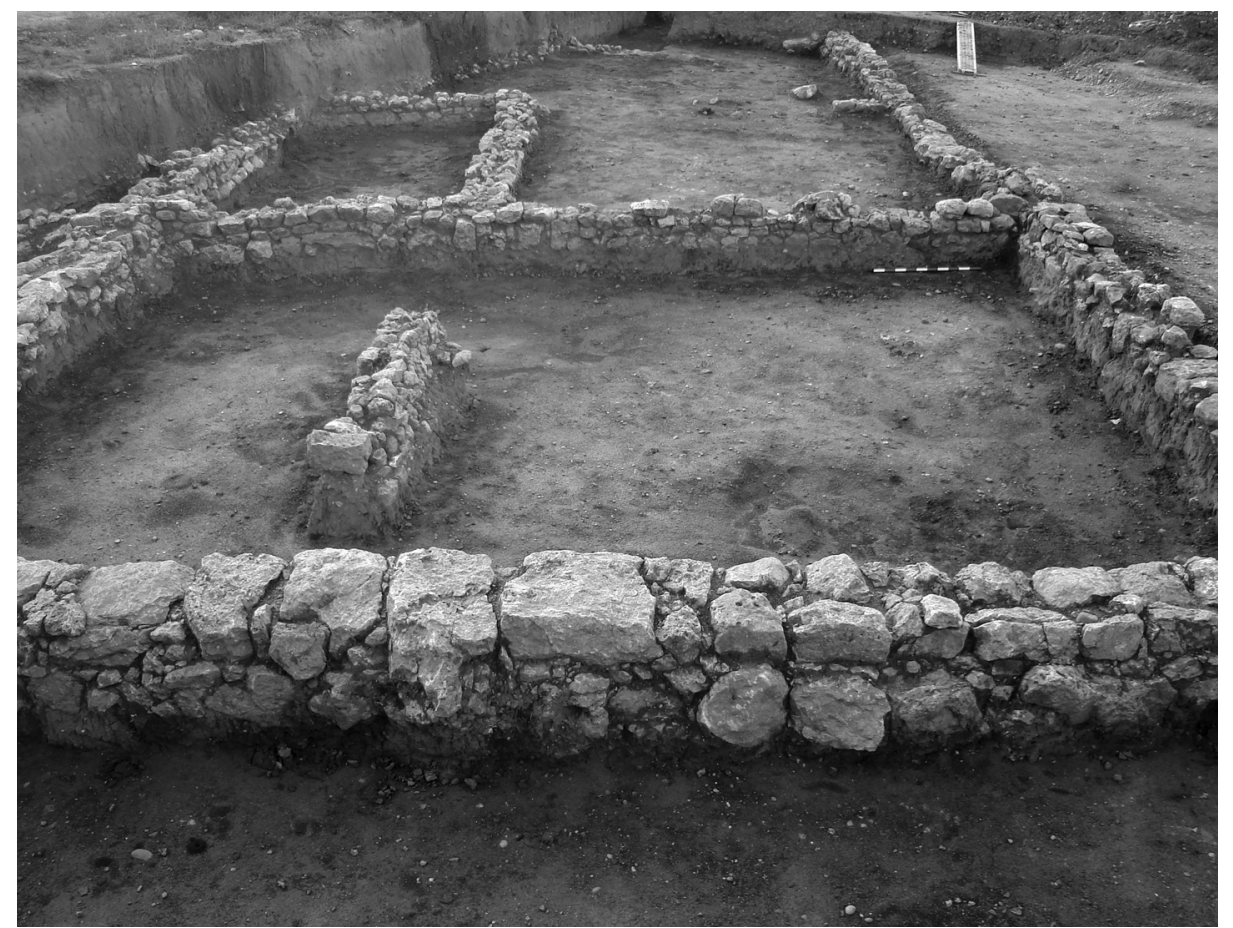

- FiguRA 2. Tabernas ubicadas en la fachada del inmueble.

La pobreza de la técnica constructiva, obligaba a rematar los muros con un revestimiento frecuentemente pintado. En este caso, se conservan restos de enfoscado, muy deteriorado, en alguno de ellos. Así mismo, se han encontrado fragmentos de ladrillos con relieve de líneas, que protegían al enlucido de la humedad (Adam 1996: 238-239).

La cubrición se realizaría mediante tegulae e imbrices, detectándose focos de relativa abundancia en algunos puntos del solar. La primera hilada de tejas de los soportales se embellecía mediante antefijas, de las cuales se han podido recuperar dos. Una de ellas muestra una cabeza femenina con media melena ondulada (fig. 2), similar a otra descubierta en el entorno de la propia Uxama (Ramos Sáinz 1996: 250). La otra representa una máscara teatral cómica y barbada. Su presencia alude, más bien, a un carácter público del espacio. La pervivencia de estas terracotas en la Meseta se establece entre el siglo I a. C. e inicios del II d. C. (Ramos Sáinz 1996: 32).

Aunque no se han localizado pavimentos asociados al edificio, sí se han recuperado ladrillos romboidales y rectangulares, de pequeño tamaño, y otros mayores fragmentados. Concretamente, los rectangulares son frecuentes en ambientes domésticos formando pavimentos de opus spicatum (Gisbert Santonja 1999: 82), mientras que los romboidales configurarian un suelo reticulado.

En el área noreste, se ha documentado la fachada de un inmueble en un recorrido continuo de 26 metros. Su compartimentación interna consta de, al menos, seis estancias rectangulares de en torno a 5,50 metros de anchura y 8 metros de profundidad. Con posterioridad se dividió en dos módulos, mediante un aparejo de menor tamaño, de aproxima- damente 5,50 por 5 y 5,50 por 2,70 metros, respectivamente el delantero y el interior. En el núcleo de la manzana, introduciéndose bajo el perfil noreste del solar, se han identificado otros cuatro aposentos, tres de los cuales se han tabicado, igualmente con mampuestos más pequeños, en una segunda fase de ocupación del inmueble.

La localización de dos estructuras de hogar -que incluyen fragmentos cerámicos entre sus componentes-, bajo los cimientos, aporta una fecha post quem a partir de la cual se construyeron éstos. Se trata de cerámica tardoceltibérica que se data en el siglo I a. C. y gran parte de la primera mitad del I d. C. (García Merino y Sánchez Simón 1997: 31).

Un análisis preliminar de los restos de cultura material ha permitido determinar el inicio de la ocupación, y uno de los momentos de máxima intensidad, en los mandatos de Claudio y Nerón (años 41 a 68 d. C.) con un segundo repunte durante los últimos años del siglo I y el II, período en el que podrian encuadrarse las reformas observadas. A finales de la tercera centuria, el enclave había perdido su carácter urbano construyéndose en las inmediaciones una villa, que pervivió hasta el siglo $\mathrm{V}$, con motivo de cuyos usos se alterarían los niveles preexistentes.

Tanto la estructura arquitectónica como la utilización de elementos latericios -ladrillos, tejas y terracotas-indican un amplio grado de romanización ya que este tipo de materiales no se generaliza en la construcción doméstica indígena hasta mediados del siglo I d. C. (Roldán Gómez 1999: 190; Durán Cabello 1999: 219).

Estos restos se han interpretado como una vivienda de tipo ínsula, con patio interior, tabernas y pórtico abiertos a 
A Figura 3. Antefija con representación de cabeza femenina.

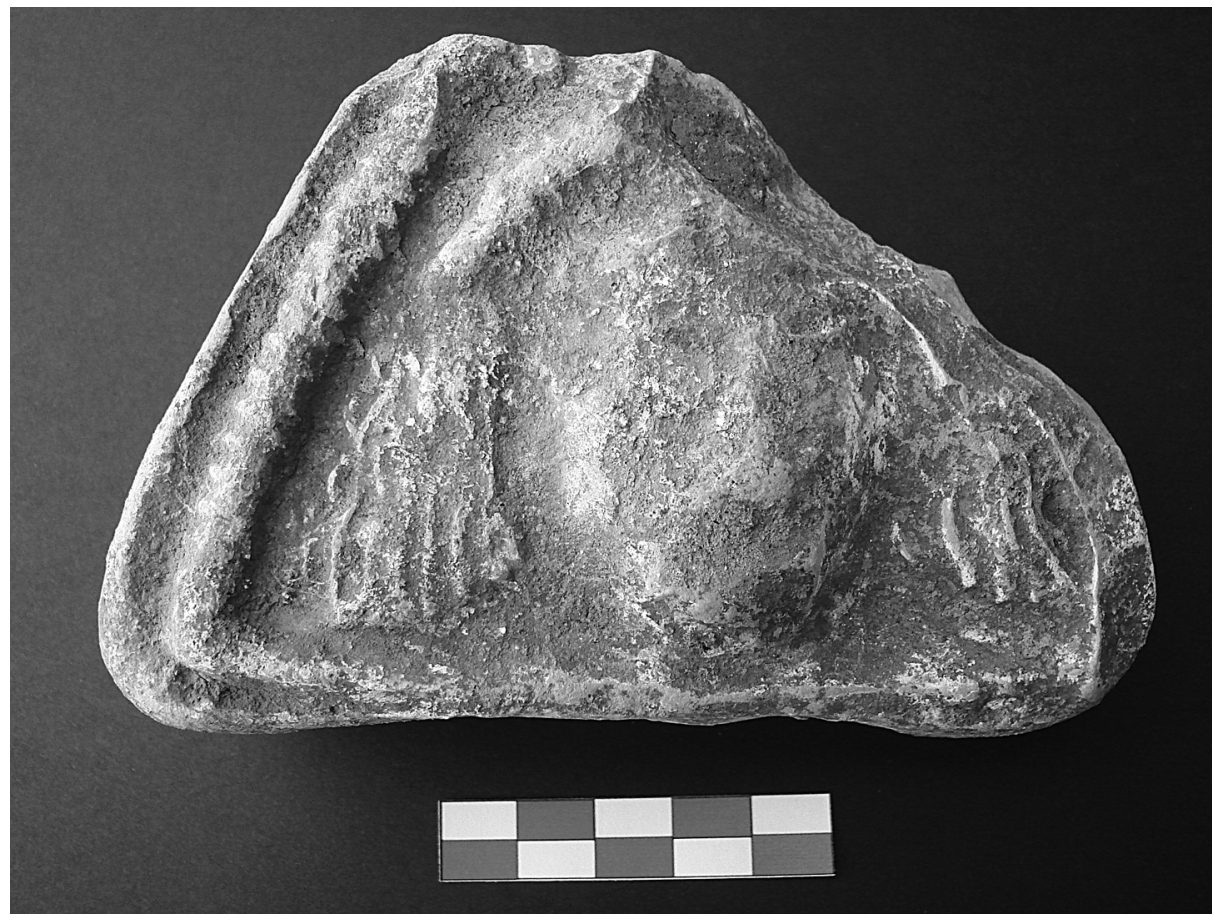

la calle (fig. 3). En una fase posterior se compartimentan las estancias y el patio. Era habitual en el mundo romano que los locales comerciales o artesanales ocuparan las fachadas de las casas o las plantas bajas de edificios altos, constando de una única estancia con una dependencia privada en la parte trasera o una escalera de acceso a la planta superior (Adam 1996: 347-348). En cuanto a su actividad concreta, se podrá determinar a partir de un exhaustivo análisis de los materiales recuperados. Entre ellos contamos con el calculus, objeto de este artículo, que se encontró sobre la superficie de la vía pública.

\section{LA FICHA DE JUEGO}

\subsection{Descripción}

Calculus o ficha de juego sobre piedra caliza de color beige, posiblemente alabastro de poca calidad. Sus dimensiones son 2,2 cm de diámetro y 0,5 cm de grosor. Presenta decoración en anverso y reverso, en ambos casos inacabada.

\subsection{Decoración e iconografía}

Anverso: aparece la representación de un elemento vegetal decapétalo que interpretamos como posible palma. La palma se distribuye radialmente teniendo el peciolo como eje, de manera que quedan distribuidas cinco puntas a la derecha y otras cinco a la izquierda. En ambos laterales aparecen mejor definidas las tres puntas centrales, mientras que los extremos superiores e inferiores están inconclusos. El diseño del motivo ofrece una configuración circular para adap- tarse a la morfología de la ficha (fig. 4). La palma es el símbolo de la victoria, fue empleada en las fichas como representación propiciatoria del triunfo en el juego que se emplease.

Reverso: muestra la letra $P$ inacabada, orientada a la 1 de las agujas del reloj. La $P$ está formada por dos trazos paralelos en la parte central e inferior para engrosarse en la zona superior; es aqui donde aparece esbozado el hueco que permite identificar la representación como letra $P$ (fig. 5). Como dato significativo hay que reseñar que la base de la $P$ está sin cerrar. En cuanto al posible significado de la letra, es difícil de apuntar, aunque no debemos descartar que haga referencia a alguna expresión del juego relacionada con la victoria.

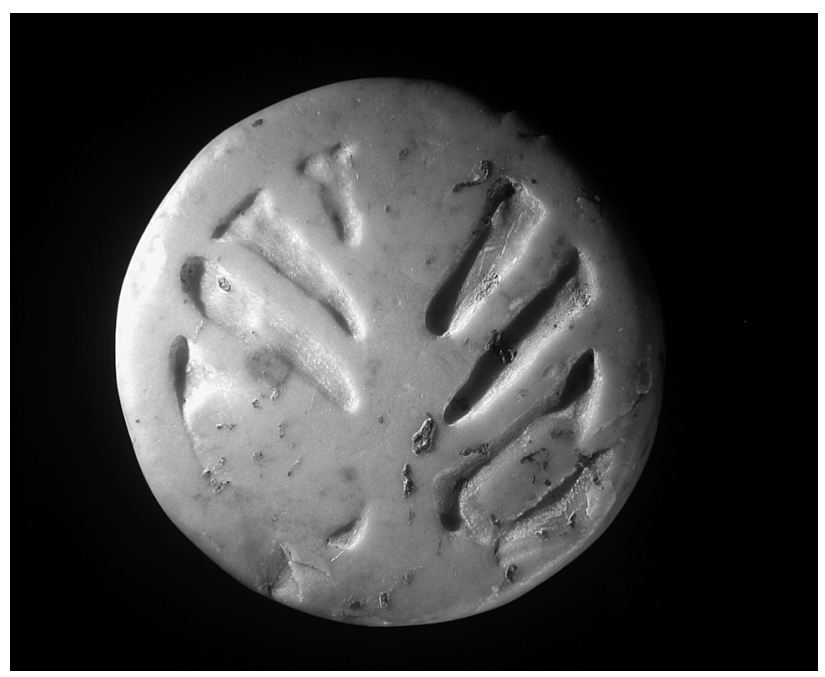

A Figura 4. Anverso de la ficha con motivo vegetal de palma. 


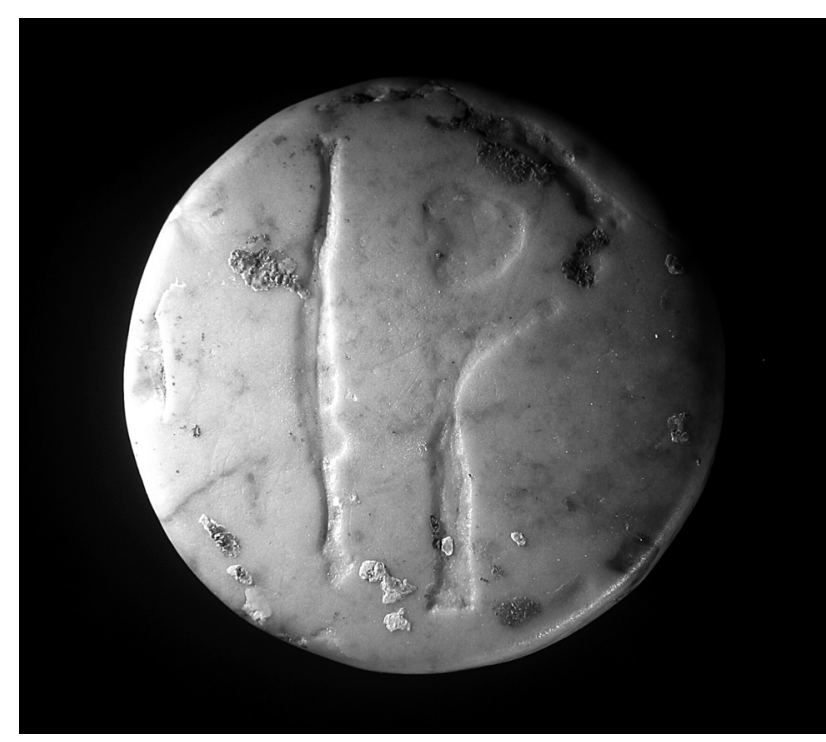

$\Delta$ Figura 5. Reverso de la ficha con letra $P$.

\subsection{Proceso de fabricación: estudio de trazas e instrumental empleado}

El anverso revela que el diseño fue dibujado previamente y sobre este patrón se llevó a cabo el grabado y posterior vaciado de los limbos de la palma. El instrumento empleado puede haber sido un pequeño cincel de punta rectilínea y perfil en $\mathrm{V}$ utilizado para marcar el comienzo de la zona a rebajar. En algunas puntas se observa como el trabajo se inició desde ambos extremos, interior y exterior, mientras que en otras se ataca únicamente desde el extremo más externo. Además, en el extremo exterior de la quinta punta del lado izquierdo, empezando por la base, se constatan dos improntas circulares aguzadas que pueden corresponder a una especie de punzón o instrumento circular, empleado inicialmente para marcar los ángulos de la zona a rebajar y empezar desde ellos la labor de rehundimiento. Es probable que este proceso haya sido empleado en el resto de las puntas pero el trabajo posterior ha borrado dichas huellas.

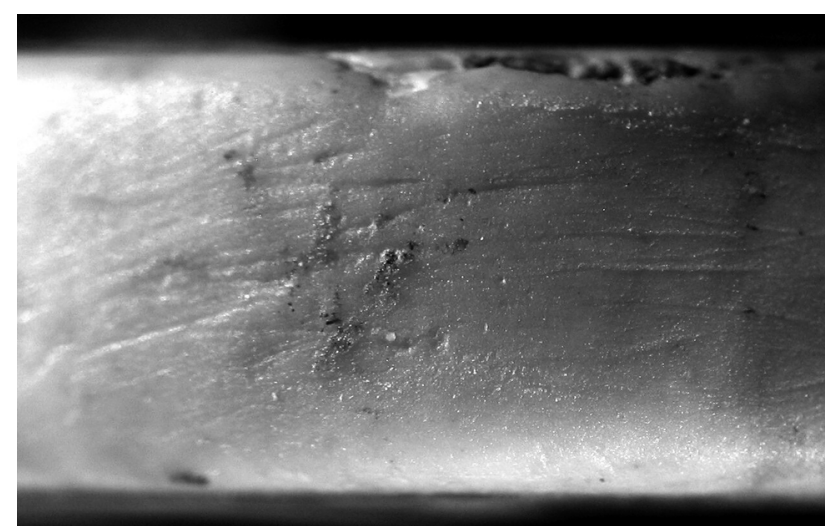

A Figura 6a y b. Estrías y roturas del proceso tecnológico.
El grabado de las puntas de palma no parece haber seguido un orden preciso pero queda claro que tras estampillar el dibujo con grafito $u$ otro material similar se marcaban las lineas principales, especialmente los ángulos de las esquinas, para evitar que el diseño se borrase a lo largo del trabajo.

Por su parte, en el reverso, parece que se emplean otros instrumentos y técnica distinta al anverso. En el brazo izquierdo de la letra $P$ se utiliza un punzón para abrir surco. En la parte central de dicho surco se ha vuelto a incidir con el instrumento en ángulo más bajo para conseguir un trazado más ancho. El vástago derecho de la $P$ muestra la incidencia de un pequeño cincel que deja una huella más ancha y plana sobrepuesta a un surco previo a punzón. El punto interior de la $P$ ha sido señalado con una especie de troquel subtriangular cuyo interior apenas ha sido rebajado. El lado curvo de la $P$ evidencia un trabajo inconcluso constituido por un ángulo agudo marcado mediante punzón a percusión directa que no acaba de enlazar con el trazo derecho de base de la letra; el uso de la percusión directa impide ejecutar curvas precisas, de ahí el trazado anguloso que ofrece y que seguramente podría ser rematado mediante un repasado con incisión (fig. 6 a y b).

Tanto en el canto de la ficha como en sus caras se observan huellas de la manufactura de la pieza. Se trata de estrias anchas en los huecos basales que representan al limbo, apreciables únicamente con un microscopio estereoscópico. Igualmente en el canto de la ficha se documentan grupos de estrías más finas producidas en el proceso de alisamiento del contorno (fig. 7). Por otra parte se aprecian pequeñas melladuras en las esquinas tanto de las caras como del canto de la pieza, algunas de ellas producto del proceso de talla y otras, probablemente, debidas a procesos postdeposicionales, pero en dos muescas opuestas parece intuirse la huella de una suerte de mordaza para sujetar la pieza durante el grabado. Igualmente, se observa un fuerte redondeamiento en las esquinas del canto así como en las aristas de los motivos, hecho que puede deberse tanto a un uso intenso, pese a estar inacabada, como a los procesos postdeposicionales ya mencionados.

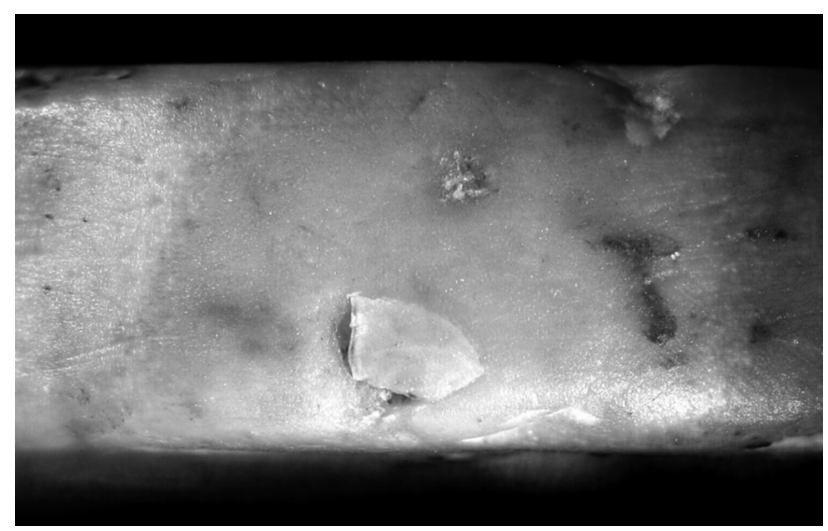




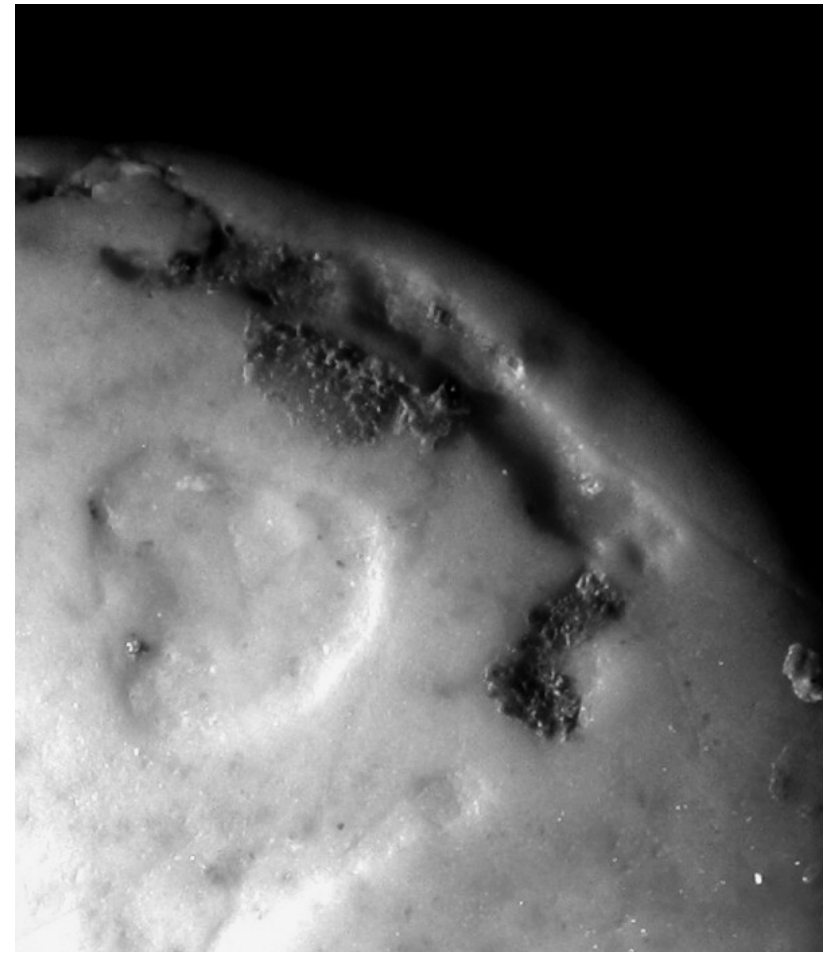

A Figura 7. Detalle del trabajo de incisión en la $P$.

El instrumental empleado debía ser muy parecido al que utilizasen los tallistas de piedras preciosas y semipreciosas. De este tipo de instrumental apenas si sabemos nada y las pocas noticias que tenemos provienen de Plinio ( $N H$ XXXVII, 15 y 65) donde habla de un hierro despuntado o romo denominado ferrum retusum; en él se insertaban pequeñisimos trozos de diamante o de ostracias u ostracites, que es una especie de variedad del ágata aunque de mayor dureza ( $N H$ XXXVII, 65) y su nombre está motivado por la similitud entre dicho material y las ostras, permitiendo cortar las materias más duras. La piedra estaba sujeta de algún modo al banco de trabajo, con una especie de cuño o mordaza, aunque se desconocen las herramientas específicas usadas en piedras duras.

Uno de los detalles más importantes en el trabajo de las piedras preciosas y semipreciosas es el del pulido de la superficie. El material empleado para tal fin no es dado a conocer por autores clásicos, sin embargo, especialistas como Casal García, opinan que debería utilizarse polvo de esmeril (smyris) o polvo de gres de Levante (naxium) e incluso apunta la posibilidad del uso de polvo de ostracias (Casal García 1990: 34).

\subsection{La ficha en el contexto de los juegos romanos y paralelos arqueológicos}

Los juegos de tablero (tabulae lusoriae) fueron muy populares entre los romanos. En la mayoría de los casos dichos tableros se realizaban sobre lajas de piedras fácilmente erosionables, tipo pizarra; en otras ocasiones sobre ladrillos o simples planchas de arcilla cocida. Sin embargo, los que más y mejor conocemos son los tableros que se grababan en plena vía pública: aceras, gradas de los edificios de ocio (Bendala 1973); enlosados de las plazas como el foro, etc. ${ }^{11}$. No obstante, las excavaciones han dado a conocer algunos ejemplares de tableros, realizados en maderas nobles y con rebordes metálicos, generalmente de bronce. En este sentido cabe reseñar el hallazgo de un tablero de juego con sus correspondientes fichas bicolores en contexto funerario, concretamente apareció como una de las piezas del ajuar en la tumba de un médico en la necrópolis de Colchester en Reino Unido ${ }^{12}$ (Crummy 1987).

Entre los juegos que utilizan este tipo de fichas bicolores (correspondientes a dos jugadores), destacamos ${ }^{13}$ :

- Duplum molendium, que se conoce también como "molino" o alquerque. Necesita un total de 24 calculi, 12 de cada color. Este mismo juego posee también una variedad que tiene como peculiaridad el contar con un total de 18 fichas, esto es 9 para cada jugador. Este juego se sigue realizando durante la Edad Media.

- Duodecim Scripta, para el que se precisa un total de 15 fichas por jugador -sólo podian participar dosasí como tres dados (tesserae). Algunos autores lo ven como el precedente del actual backgammon.

- Latrunculi, traducido como juego de los ladrones o de los mercenarios, es parecido a nuestras "damas" actuales. Consta de un tablero de diferentes formas y casillas, puede ser cuadrado -de 8 por 8- o rectangular -de 11 por 10-. Dependiendo del número de casillas corresponde un número distinto de fichas, aunque ambos jugadores deben tener el mismo número de ellas.

- Terni Lapilli, se corresponde con nuestro actual "tres en raya" y, como ahora, sólo se precisaba de tres fichas por jugador.

(11) Hay que precisar que estas piezas, tanto calculi como tabulae lusoriae, reciben el consabido tratamiento patrimonial como se demuestra en trabajos como el de Llanos 2002.

(12) Para ver la imagen del hallazgo ir a http://www.romanglassmakers.co.uk/games.htm

(13) Cfr. Lillo 2005 y Costas e Hidalgo 1997. 


\section{BIBLIOGRAFÍA}

AdAM, J. P., 1996: La construcción romana, materiales y técnicas. Editorial de los Oficios. León.

ANDRÉ, J.M., 1992: Jeux et divertissements dans le monde greco-romain. Jeux et jouets dans l'antiquite et le moyen age. Les Dossiers d'archeologie 168, 36-45.

Arellano, 0.; Barrio, R.; Lerin, M.; Ruiz, A. y Tarancón, M.J., 1999: Excavación arqueológica realizada para delimitar la villa romana de "Las Dehesas" (Osma, Soria). Informe depositado en el Servicio Territorial de Cultura de Soria.

BendALA, M., 1973: Tableros de juego en Itálica. Habis 4, 266-269. Universidad de Sevilla.

BENÉVOLO, L., 1979: Introducción a la arquitectura. Biblioteca Básica de Arquitectura. E. Blume. Madrid.

Blanco Frejelro, A., 1981: Historia del Arte Hispánico I. La Antigüedad 2. Ed. Alhambra. Madrid.

Casal Garcia, R., 1990: Colección de glíptica del Museo Arqueológico Nacional (Serie de entalles romanos). Dirección General de Museos Estatales. Madrid.

COSTAS Goberna, F. J. y Hidalgo CuñarRo, J.M., 1997: Los juegos de tablero en Galicia. Aproximación a los juegos sobre tableros en piedra desde la antigüedad clásica hasta el medievo. Artes Gráficas Vicus, S.L. Vigo.

Coulon, G., 1994: L'enfans en Gaule Romaine. Editions Errances. Paris (France).

CRUmmY, N., 1987: The roman small finds from excavations of Colchester 1971-9. Colchester Archaeological Report 4.

Daremberg, Ch. y SAglio, E., 1811: Dictionarie des Antiquetés grecques et romans. Volume III, 2. Akademische Druck - $n$ Verlagsanstalt graz. Austrie (Reeditado en 1969).

Durán Cabello, R.M., 1998: La arquitectura pública en Complutum. Elementos decorativos y materiales constructivos. Complutum, Roma en el interior de la península, 95-105.

Durán Cabello, R. M., 1999: El uso del ladrillo en la arquitectura de Augusta Emerita. El ladrillo y sus derivados en época romana. Monografias de arquitectura romana, 4. Universidad Autónoma de Madrid. Madrid.

Fernández Vega, P.A., 1993: Arquitectura y urbanistica en la ciudad romana de Julióbriga. Universidad de Cantabria. Santander.

FERnÁNDEZ VegA, P.A., 1999: La casa romana. Ed. Akal. Madrid.

FIITÁ, M., 1997: Giochi e giocattoli nell'Antichità. Leonardo Arte. Milano.

Garcia Merino, C., 1987: Promoción política y desarrollo urbano de Uxama Argaela. Boletín del Seminario de Arte y Arqueología LXXX. VaIladolid.

Garcia Merino, C., 1991: La casa urbana en Uxama Argaela. La casa urbana hispanorromana, 233-260.

Garcia MeRINO, C., 1995: Uxama I (1976-1978). Excavaciones Arqueológicas en España, 170. Ministerio de Cultura. Madrid.

García Merino, C., 1999: Urbanización y ordenación del territorio en Uxama Argaela. Actas da mesa redonda. Emergência e desenvolvimiento das cidades romanas no Norte da Península lbérica. Escola Profissional de Arqueologia, Instituto Português do Património Arquitectónico y Programa Operacional do Norte. Porto.
Garcia Merino, C., 2005: Uxama Argaela. En Chaín Galán y Torre Echávarri (coor.) Celtiberos: tras las estela de Numancia, 177-182.

Garcia Merino, C. y SÁnchez Simón, M., 1997: Uxama II. La casa de la atalaya. Studia Archaeologica 87. Universidad de Valladolid. Zaragoza.

Gisbert SAntonja, J. A., 1999: El alfar de L'Almadrava (Setla-MirarosaMiraflor) -Dinium-. Materiales de construcción cerámicos. Producción y aproximación a su funcionalidad en la arquitectura del complejo artesanal. El ladrillo y sus derivados en época romana. Monografias de arquitectura romana, 4. Universidad Autónoma de Madrid. Madrid.

LiLlo ReDonet, F., 2004: Ludus. ¿Cómo jugar como los antiguos romanos? Librería Áurea Clásicos, Madrid.

LiLlo Redonet, F., 2005: Los juegos romanos. Una inmersión en el Mundo Clásico. Iris 15.

Llanos ORtiz de LANDaluze, A., 2002: Tableros de Juego en el patrimonio arqueológico de Álava. Estudios de Arqueología Alavesa 19, 191196.

MARINÉ, M., 1992: Las villas romanas en la provincia de Soria: estado de la cuestión. II Symposium de Arqueología Soriana, tomo II. Soria.

Moreno Gallo, l., 2002: Caracteristicas técnicas de la vía romana de Zaragoza a León. Actas del I Congreso Internacional de Caminería Hispánica (Valencia, 2000). Ministerio de Fomento. Madrid.

Ponte, S. da, 1986: Jogos romanos de Conímbriga. Conímbriga 25, 131141. Universidade de Coímbra.

Ponte, S. da, 1999: Jogos e passatempos romanos. Castrelos 12: 141168. Museo Municipal "Quiñones de León" de Vigo.

PoTteR, T.W., 1979: Romans in North-West England. Kendal. Titus Wilson \& Son, Ltd.

Ramos SÁinz, M.L., 1996: Las terracotas arquitectónicas en la Hispania Romana: la Tarraconense. Monografias de arquitectura romana, 3.1. Universidad Autónoma de Madrid. Madrid.

RIECHE, A., 1984: So Spielten die Alten Romër. Römische Spiele im Archäologischen Park Xanten. Palmer Druck, Bergish Gladbach. Köln.

RoLDÁN GómEZ, L., 1999: Arquitectura pública en las ciudades de la Bética. El ladrillo y sus derivados en época romana. Monografias de arquitectura romana, 4. Universidad Autónoma de Madrid. Madrid.

Romero CARNICERO, M.V., 1992: La romanización en la provincia de Soria. Panorama y perspectivas. II Symposium de Arqueología Soriana, tomo II. Soria.

Salza Prima Rocoti, E., 1996: Vita e costumi dei romani antichi. Museo della Civiltá Romana 18. Edizioni Quasar. Rome.

Taracena AguirRe, B., 1934: Vias romanas del Alto Duero. Anuario del Cuerpo Facultativo de Archiveros, Bibliotecarios y Arqueólogos. Volumen II. Madrid.

\section{Páginas Web}

http://www.aerobiologicalengineering.com/wxk116/Roman/BoardGames/ rbrefers.html

http://www.novaroma.org/nr/

http://www.romanglassmakers.co.uk/games.html 